\title{
Multi-scale observations of magnetotail flux transport during IMF-northward non-substorm intervals
}

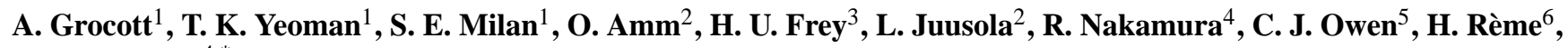 \\ and T. Takada ${ }^{4, *}$ \\ ${ }^{1}$ Department of Physics \& Astronomy, University of Leicester, Leicester LE1 7RH, UK \\ ${ }^{2}$ Finnish Meteorological Institute, P.O. Box 503, 00101 Helsinki, Finland \\ ${ }^{3}$ Space Sciences Lab, University of California, Berkeley, CA 94720-7450, USA \\ ${ }^{4}$ Space Research Institute, Austrian Academy of Sciences, Schmiedlstrasse 6, Graz, 8042, Austria \\ ${ }^{5}$ Mullard Space Science Laboratory, University College London, Holmbury St. Mary, Dorking, Surrey, RH5 6NT, UK \\ ${ }^{6}$ CESR, 9 avenue du colonel Roche, Toulouse, 31028, France \\ *now at: Solar-Terrestrial Physics Group, Institute of Space and Astronautical Science, Japan Aerospace Exploration Agency, \\ Yoshinodai 3-1-1, Sagamihara 229-8510, Japan
}

Received: 9 February 2007 - Revised: 29 June 2007 - Accepted: 13 July 2007 - Published: 30 July 2007

\begin{abstract}
Simultaneous observations by the Cluster spacecraft and SuperDARN radars are presented of magnetotail flux transport during northward, but $B_{Y}$-dominated IMF. Two events are discussed, which occurred on 14 August 2004 and 17 September 2005, during intervals of negative and positive IMF $B_{Y}$, respectively. During both intervals the Cluster spacecraft observed isolated bursts of Earthward plasma convection in the central plasma sheet. During the first event, the flows observed by Cluster also had a significant $V_{\perp Y}$ component in the duskward direction, consistent with westward azimuthal flows observed in the midnight sector by the Northern Hemisphere SuperDARN radars. During the second event, Cluster 4 observed a significant dawnward $V_{\perp Y}$ component, again consistent with the Northern Hemisphere SuperDARN observations which revealed eastward azimuthal flow. In this instance, however, Cluster 3 observed a duskward $V_{\perp Y}$ component which was more consistent with the duskward sense of the convection observed by the Southern Hemisphere SuperDARN radars. This implies that Cluster 3 and Cluster 4 were located on different field lines which experienced opposite net azimuthal forces and hence observed oppositely directed convection. These observations are consistent with previous SuperDARN studies of nightside flows under northward IMF and, more importantly, provide the first simultaneous in-situ evidence for a mode of tail reconnection occurring during non-substorm intervals in an asymmetric tail.
\end{abstract}

Keywords. Ionosphere (Ionosphere-magnetosphere interactions; Plasma convection) - Magnetospheric physics (Magnetotail)

Correspondence to: A. Grocott

(a.grocott@ion.le.ac.uk)

\section{Introduction}

The concept of twin-vortex "Dungey-cycle" magnetospheric convection has been understood for many years (e.g. Dungey, 1961). Typically during intervals of southward IMF, reconnection at the dayside low-latitude magnetopause causes closed terrestrial field lines to become connected into the solar wind, adding open flux to the polar caps. This flux is transported anti-sunward at high-latitudes over the northern and southern polar caps by the flow of the solar wind, into the tail lobes. Here it convects equatorwards, ultimately reconnecting again in the central plasma sheet, becoming closed once again. This newly closed flux then convects back to the dayside at lower-latitudes via dawn and dusk completing the twin-vortex convection pattern with which we are familiar. The physical process by which the tail component of this reconnection cycle occurs is often associated with magnetospheric substorms (Hones, 1979; Farrugia et al., 1993; Baker et al., 1996; Nagai et al., 1998). Although the finer details of causality during substorms are still highly debated, it is generally accepted that substorms are responsible for a large fraction of magnetotail flux transport (Hones, 1979; Baker et al., 1996). This is often observed to occur in the form of bursty bulk flows (BBFs) (Baumjohann et al., 1990; Angelopoulos at al., 1992, 1994) or rapid flux transport events (RFTs) (Schödel et al., 2001a, b) which are essentially localised, transient, packets of fast moving magnetic flux.

The nature of the twin-vortex convection excited in the ionosphere in association with the onset and expansion phase of magnetospheric substorms has been demonstrated by Grocott et al. (2002) and Provan et al. (2004). Macroscale convection features associated with isolated BBFs have also been investigated by Grocott et al. (2004a) and Nakamura et

Published by Copernicus Publications on behalf of the European Geosciences Union. 
al. (2005a) during intervals of relative quiet preceding major substorm expansions. In addition, a new mode of large-scale magnetotail flux transport which appears to dominate during intervals of northward, but $B_{Y}$-dominated IMF, has been observed in HF ionospheric radar data as reported by Grocott et al. $(2003,2004 b, 2005)$. This takes the form of highly asymmetric Dungey-cycle twin-vortex convection, with bursts of fast azimuthal flow in the midnight sector accompanying intervals of modest flux closure. Grocott et al. (following earlier work by Sandholt et al., 1998a, b) suggest that dayside reconnection equatorward of the cusp persists during such intervals of intermediate IMF clock angle (in addition, perhaps, to high-latitude reconnection usually associated with northward IMF), and that this drives a moderate convection cycle which is not sufficient to trigger magnetospheric substorms. Milan et al. (2005) coined the term "tail reconnection during IMF-northward, non-substorm intervals" (TRINNIs) to describe this phenomenon, which recurs on timescales of tens of minutes, and acts to balance the low-level open flux creation at the dayside. The lack of associated substorm signatures such as geosynchronous particle injections and global auroral expansions implies that that this reconnection is occurring at a more distant neutral line, rather than the nearEarth neutral line which is activated at substorm onset.

The dependence of the orientation of TRINNI flows on IMF $B_{Y}$, as well as the interhemispheric asymmetry which they display, has led several authors (including Nishida et al., 1995, 1998; Grocott et al. 2004b, 2005) to suggest a mechanism for their generation based on the idea of magnetic field reconfiguration following reconnection in a twisted tail. This follows earlier work by Taguchi (1992), Taguchi et al. (1994), Taguchi and Hoffman (1996) who reported Magsat observations of IMF $B_{Y}$-controlled field-aligned currents near the midnight auroral oval and associated DE-2 observations of azimuthal plasma convection. Essentially, the effect of prolonged exposure to significant IMF $B_{Y}$ is to introduce an azimuthal separation between the Northern and Southern Hemisphere footprints of a reconnecting tail field line, such that newly reconnected flux would have to travel faster in one hemisphere to convect, via dusk or dawn, back to the dayside. It is proposed that this is what then gives rise to the fast bursts of flow observed in the nightside ionosphere, however, no in-situ magnetospheric observations have yet been reported which support this idea. In this paper, in-situ observations of magnetotail flux transport from the Cluster spacecraft are presented along with simultaneous ground-based radar observations of the large-scale ionospheric flow. It is revealed that TRINNIs are associated with bursty bulk flows, but ones which have a significant azimuthal velocity component matching that of the large-scale convection evident in the ionosphere. Furthermore, in-situ observations from either side of the tail current sheet reveal convective flow with opposite azimuthal sense. This provides compelling evidence for a twisted tail containing field lines which are aligned significantly out of a meridian plane, lend- ing weight to the proposed mechanism by which this new mode of magnetospheric convection transports flux in the tail.

\section{Instrumentation}

The observations discussed in this paper were made during two intervals: 21:50-22:20 UT on 14 August 2004 (henceforth referred to as I-1) and 00:55-01:25 UT on 17 September 2005 (henceforth referred to as I-2). In-situ magnetotail observations were made by the Cluster spacecraft during both intervals. The Composition and Distribution Function Analyzer (CODIF) sensor and the Hot Ion Analyser (HIA) of the Cluster Ion Spectrometry (CIS) instrument (Rème et al., 2001) provided ion velocity data for the events, and magnetic field data were provided by the fluxgate magnetometer (FGM) (Balogh et al., 2001). The positions of the spacecraft in the magnetosphere at the midpoint of each interval (22:05 UT for I-1 and 01:10 UT for I-2) are illustrated in Fig. 1a. The top panel shows the geocentric solar magnetic (GSM) $x-z$ plane, the middle panel shows the $x-y$ plane and the bottom panel shows the $y-z$ plane. In all three panels Cluster 1 (black) lies on the solid field line for I-1 and the dashed field line for I-2. These field lines are the T-96 model field lines (Tsyganenko, 1995). Spacecraft 2-4 (red, green and blue, respectively) have had their positions relative to Cluster 1 expanded (by a factor of 10 for I- 1 and 2 for I-2) for clarity.

Measurements of ionospheric convection from both intervals were provided by the Super Dual Auroral Radar Network (SuperDARN) radars (Greenwald et al., 1995). SuperDARN is an international collaboration of HF radars located in the auroral regions of both hemispheres, which provide routine observations of the horizontal ionospheric plasma flow. The flow measurements made during both intervals discussed here are thus used to infer the large-scale nature of magnetospheric-ionospheric convection via the derivation of large scale maps of the high-latitude convection using the "Map Potential" model (Ruohoniemi and Baker, 1998). This technique involves the mapping of line-of-sight radar velocity measurements onto an equal area polar grid and using them to determine a solution for the electrostatic potential, expressed in spherical harmonics up to sixth order. The equipotentials of the solution represent the plasma streamlines of the modelled convection pattern. Information from the statistical model of Ruohoniemi and Greenwald (1996), parameterised by concurrent IMF conditions, is used to stabilise the solution where no data are available. A HeppnerMaynard boundary, determined from the line-of-sight velocity data, is also used to constrain the convection pattern at lower latitudes (Heppner and Maynard, 1987; Shepherd and Ruohoniemi, 2000).

Figures $1 \mathrm{~b}-\mathrm{c}$ show the fields-of-view of SuperDARN plotted for I-1 at 22:05 UT in the Northern and Southern 

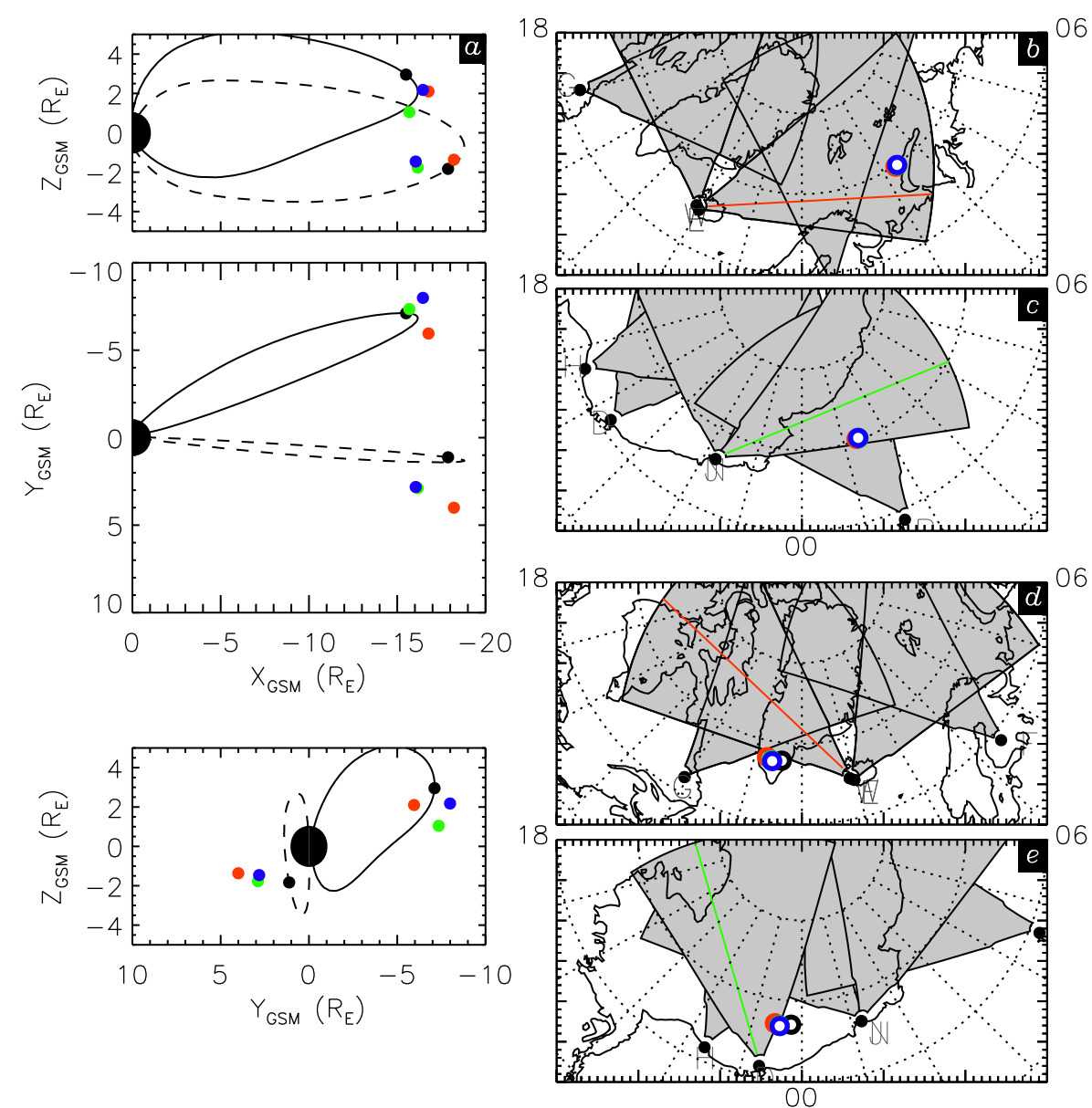

Fig. 1. (a) The location of the Cluster 1 spacecraft (black circle) in the $x-z$ (top panel), $x-y$ (middle panel) and $y-z$ (bottom panel) GSM planes, superposed on its T-96 model field line (drawn solid for 22:05 UT on 14 August 2004 and dashed for 01:10 UT on 17 September 2005). Spacecraft 2-4 (red, green and blue circles, respectively) are also shown, but with their positions relative to Cluster 1 expanded (by a factor of 10 for the first interval and a factor of 2 for the second) for clarity. (b) Northern and (c) Southern Hemisphere SuperDARN radar fields-of-view drawn at 22:05 UT on a magnetic latitude-magnetic local time grid of the nightside ionosphere, with 18:00, 00:00 and 06:00 MLT marked. Iceland East-beam 12 and Syowa East-beam 10 are marked by the red and green lines, respectively. The T-96 mapped Cluster footpoints for 14 August 2004 are indicated by the coloured circles. (d-e) As (b-c), but for 01:10 UT on 17 September 2005, with Iceland West-beam 8 (red) and Sanae-beam 2 (green) shown.

Hemispheres, respectively, and Figs. 1d-e show them plotted for I-2 at 01:10 UT. These are presented in magnetic local time- (MLT) magnetic latitude coordinates on grids of the Northern (panels b and d) and Southern (panels c and e) Hemispheres (all viewed as if looking down from the north). Also shown are selected radar beams, indicated by the red and green lines. These are (b) Iceland East-beam 12, (c) Syowa East-beam 10, (d) Iceland West-beam 8 and (e) Sanae-beam 5. The ionospheric footprints of the Cluster spacecraft for I-1 and I-2 are indicated by the coloured circles, mapped into the Northern and Southern Hemispheres using the T-96 magnetic field model.

IMF conditions for each study interval were measured by the MAG instrument (Smith et al., 1999) onboard the ACE spacecraft (Stone et al., 1998). Solar wind data obtained by the SWEPAM instrument (McComas et al., 1998) were also used to estimate the propagation delay of field changes from ACE (located at L1) to the dayside ionosphere using the algorithm of Khan and Cowley (1999). This was found to be $67 \pm 2$ min for I- 1 and $48 \pm 1$ min for I- 2 .

\section{Observations}

This section details the ionospheric observations and in-situ magnetospheric measurements from the two intervals of interest. 

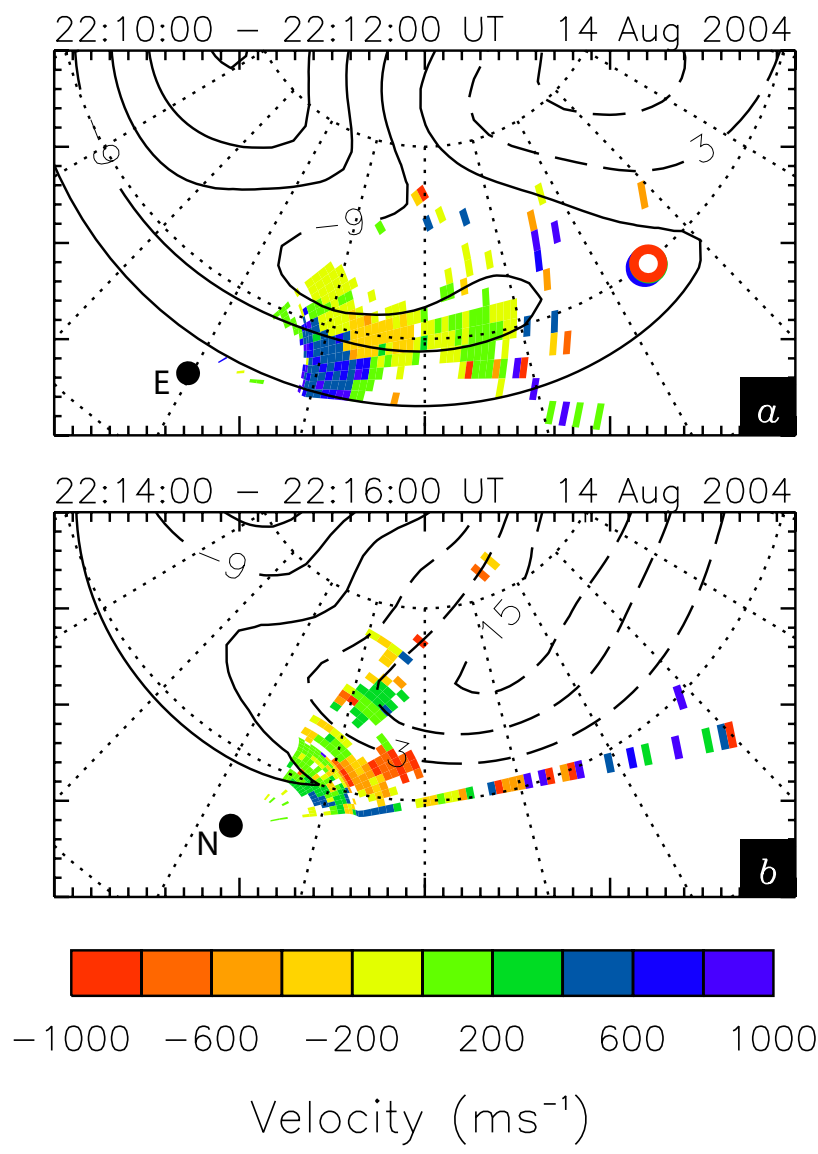

Fig. 2. (a) SuperDARN line-of-sight velocity data from the Iceland East radar at 22:10 UT on 14 August 2004 plotted on the same polar grid as in Fig. 1b. The data is colour coded according to the bar at the bottom, with positive velocities indicating flow towards the radar and negative velocities away. Contours of the ionospheric electric potential are superposed. (b) As (a) but for the Syowa East radar in the Southern Hemisphere at 22:14 UT.

\subsection{Interval 1: 14 August 2004 (21:50-22:20 UT)}

Figure 2 shows a single scan of Northern (a) and Southern (b) Hemisphere SuperDARN line-of-sight data. The locations of the radars are indicated by the filled black circles. The Northern Hemisphere scan is from the Iceland East radar (E) at 22:10 UT and the Southern Hemisphere scan is from the Syowa East radar (N), a few minutes later at 22:14 UT. The data are colour coded according to the colour bar at the bottom such that green and blue data represent positive Doppler velocities, i.e. plasma moving towards the radar, and red and yellow data represent negative Doppler velocities, i.e. plasma moving away from the radar. Superposed on these data are contours of the ionospheric electric potential (equivalently streamlines of plasma flow) derived using data from the full complement of SuperDARN radars via the Map Potential technique. The Cluster footprints from Fig. 1 are also shown on the Northern Hemisphere map for reference.
The plasma streamlines, which give an indication of the large-scale nature of the flow, reveal a number of important features. Firstly, they reveal that the large-scale flow is asymmetric about the noon-midnight meridian. Secondly, they reveal that this asymmetry has an opposite sense in each hemisphere. Thirdly, they reveal that the sense of the flow in the midnight sector is azimuthal; east-west in the Northern Hemisphere and west-east in the Southern Hemisphere. Looking at the line-of-sight data on which the streamlines are superposed reveals additional information about the macroscale nature of the flows. They are quite clearly locally enhanced, i.e. of order $1000 \mathrm{~m} \mathrm{~s}^{-1}$ in both hemispheres (the red and blue patches of scatter). They also exhibit a clear reversal (yellow to blue in the Northern Hemisphere and green to red in the Southern Hemisphere). This is consistent with the flows transitioning from open to closed field lines (discussed further in Sect. 4) with the TRINNI flows generally considered to be the low-latitude enhancement to the "return flow" of closed flux. Looking at the data from $\sim 10$ min either side also reveals that these enhanced features are transient and bursty (discussed in more detail in Sect. 4). These observations are consistent with the characteristics of IMF $B_{Y}$-negative TRINNIs which have been reported in previous studies.

The concurrent IMF conditions for this interval are summarised in Fig. 3a, which shows the 3 components of the lagged ACE magnetic field data $\left(B_{X}\right.$ : blue, $B_{Y}$ : green and $B_{Z}:$ red) between 21:50 and 22:20 UT. This shows that the interval was one of northward, but negative $B_{Y}$-dominated IMF, which is consistent with the orientation of the TRINNI flows described above. The corresponding in-situ magnetospheric observations from the Cluster spacecraft are shown in Figs. 3b-c. Panel (b) shows the GSM X and Y components of the full flow vector and of the magnetic field perpendicular component of the flow. The latter were calculated by rotating the CIS CODIF data into a magnetic field oriented coordinate system (determined using the FGM data), removing the field parallel component, then rotating back into GSM. The resulting data are then a good representation of convective motion of magnetic flux. The FGM data (in GSM coordinates) are shown in Fig. 3c. The colour coding of the Cluster data is black (C1), red (C2), green (C3) and blue (C4). The horizontal dashed lines show the concurrent T-96 model magnetic field. Vertical dashed lines indicate times of specific interest, detailed below.

The first two panels of Fig. 3b then show the earthward flux transport observed by Cluster 1 and 4 during the interval (no CIS data exist for Cluster 2 and 3 for this interval). Both spacecraft observed a clearly defined signature of a bursty bulk flow (BBF), as evidenced by the enhancement in $V_{\perp X}$ which peaked at 22:04 UT (ii) at a value of $\sim 600 \mathrm{~km} \mathrm{~s}^{-1}$. These enhanced flows were accompanied by an enhancement in $B_{Z}$ beginning at 21:57:30 UT (i) (peaking at $\sim 10 \mathrm{nT}$ after $5 \mathrm{~min}$ ), which is also indicative of flux transport via dipolarisation. Interestingly, the enhancement in $V_{\perp X}$ was also 
accompanied by a comparable enhancement in $V_{\perp Y}$. This enhancement was in a duskward direction, the same as the direction of the TRINNI flows in the Northern Hemisphere ionosphere (Fig. 2a). The corresponding (but smaller) enhancement in $V_{Y}$ reveals that the plasma was indeed accelerated in a duskward direction, although the magnetic field geometry was such that it was the field-perpendicular component of the flow which had the most significant azimuthal sense. $B_{Y}$ also showed some variability, with a positive enhancement occurring a few minutes prior to the enhancement to the flow followed by a negative enhancement coincident with the peak flows. It is difficult to comment on the significance of these signatures, but it seems reasonable that there might be some fluctuations in the azimuthal component of the magnetic field close to the reconnection site in an asymmetric tail.

At 22:07 UT (iii) all 3 components of the magnetic field dropped to zero in association with a change in sign of $V_{\perp X}$ and $V_{\perp Y}$ which suggests that Cluster moved tailward of a reconnection X-line. Although $B_{Z}$ barely went negative, which it might have been expected to do for a simple X-line geometry, it did become less positive (dropping below the T-96 model field value). This is consistent with the idea that the local reconnection geometry was in fact somewhat complex. Towards the end of the interval, in association with the end of the observed flow enhancement at $\sim 22: 13$ UT (iv), $B_{Z}$ had levelled off in line with the T-96 model field, approximately $5 \mathrm{nT}$ above its pre-interval value.

\subsection{Interval 2: 17 September 2005 (00:55-01:25 UT)}

Figure 4 shows a single scan of Northern (a) and Southern (b) Hemisphere SuperDARN line-of-sight data in the same format as Fig. 2. The Northern Hemisphere scan is from 01:08 UT and the Southern Hemisphere scan is from a few minutes earlier at 01:02 UT. The Cluster footprints from Fig. 1 are also shown; Clusters 2 and 4 are shown on the Northern Hemisphere map and Cluster 3 is shown on the southern map (because Cluster 3 is south of the neutral sheet, as will be discussed below). Because the coverage of data from any one radar is not as good for this interval as it was for I-1, scans from a number of radars are shown on the same map: Iceland East (E), Iceland West (W), and Goose Bay (G) for the Northern Hemisphere and Halley (H) and Sanae (D) for the Southern Hemisphere. These data are sufficient to derive potential patterns which have similar characteristics to those of I-1, i.e. large-scale flow that is asymmetric about the noon-midnight meridian, azimuthal in direction and with an opposite sense in each hemisphere. This asymmetry is reversed relative to I-1, however, being west-east in the Northern Hemisphere and east-west in the Southern Hemisphere.

The more localised low-latitude bursty element to the flow patterns are again revealed by the line-of-sight data. In the Northern Hemisphere the blue patch of scatter observed by the westward pointing radar and the red patch of scatter

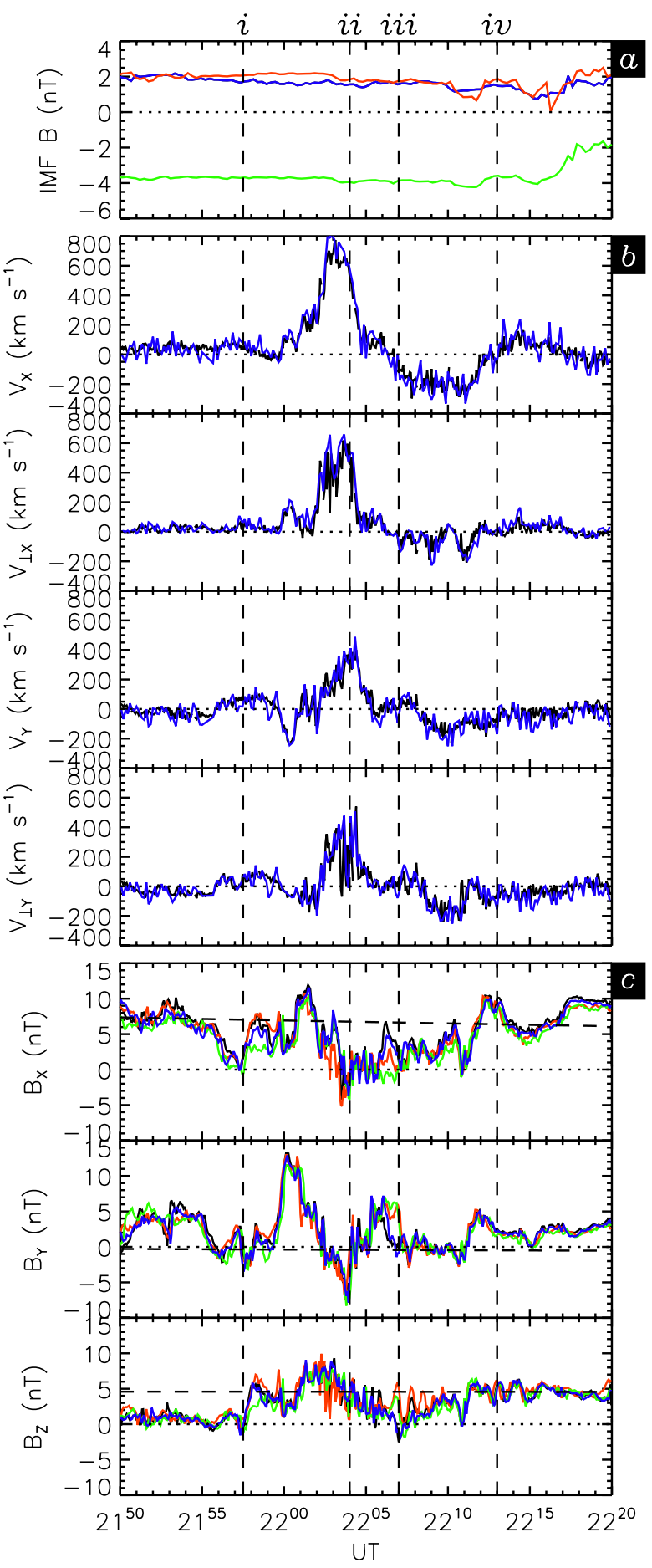

Fig. 3. Time series data from 21:50-22:20 UT on 14 August 2004. (a) The three GSM components of the lagged upstream IMF data from the ACE spacecraft: $B_{X}$ (blue), $B_{Y}$ (green), and $B_{Z}$ (red). (b) The X (top two panels) and Y (bottom two panels) GSM and magnetic field perpendicular components of the ion flow as measured by the CIS instruments on two Cluster spacecraft (same colour coding as Fig. 1a). (c) The three GSM components of the magnetic field as measured by the FGM instrument on the four Cluster spacecraft (same colour coding as Fig. 1a). The vertical dashed lines indicate specific times of interest. 

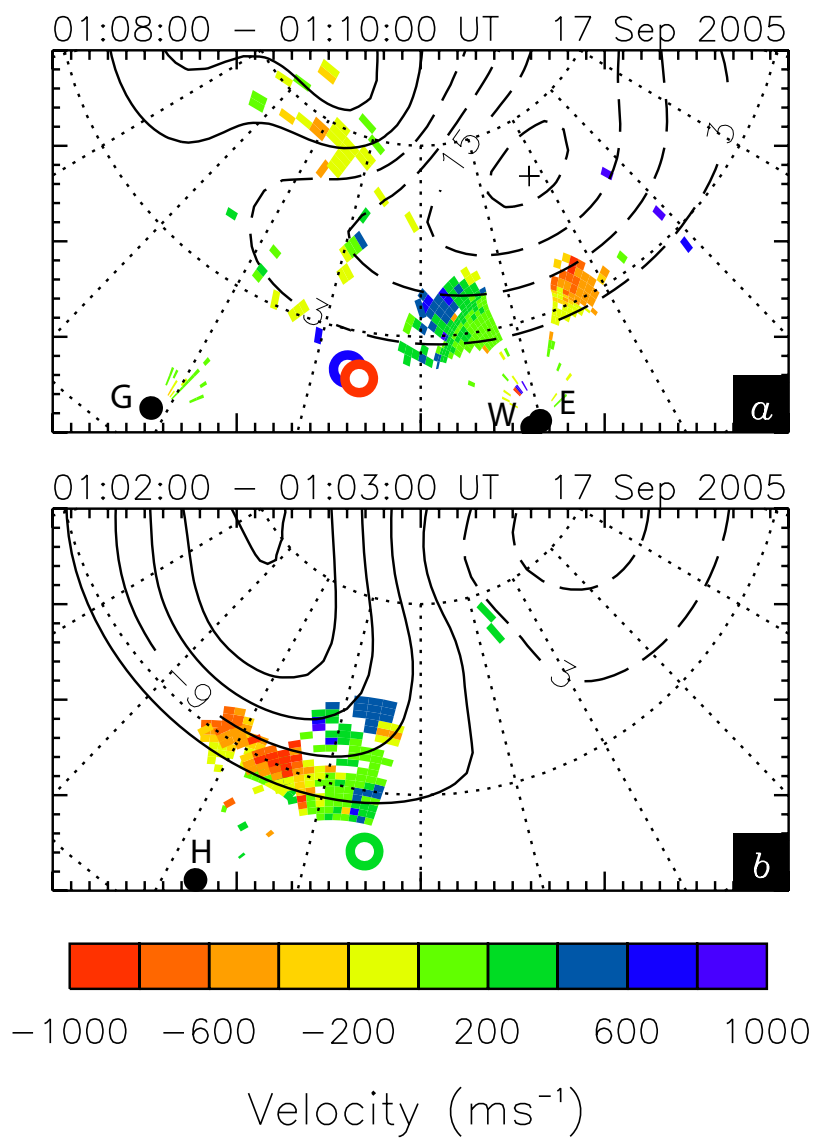

Fig. 4. (a) SuperDARN line-of-sight velocity data from the Iceland East, Iceland West, and Goose Bay radars at 01:08 UT on 17 September 2005 in the same format as in Fig. 2a. (b) As (a) but for the Halley and Sanae radars in the Southern Hemisphere at 01:02 UT.

observed by the eastward pointing radar together form the signature of an eastward flow burst of $\sim 1000 \mathrm{~m} \mathrm{~s}^{-1}$. Although the asymmetry in the Southern Hemisphere flows appears less pronounced than that in the Northern Hemisphere, there is nevertheless evidence of a burst of fast duskward flow of similar magnitude to its northern counterpart in the premidnight auroral zone (the red patch of scatter). It is possible that a lack of data in the post-midnight sector in this case is contributing to the lack of asymmetry in the derived potential pattern.

Figure 5 presents the ACE and Cluster data for this interval in the same format as that shown in Fig. 3. Figure 5a shows that this interval was one of northward, but positive $B_{Y}$-dominated IMF, opposite to I-1 and again consistent with the orientation of the TRINNI flows described above. Turning to the Cluster data, Fig. $5 \mathrm{~b}$ shows the earthward flux transport observed by Cluster 3 and 4 (no CIS data exist for Cluster 1 or 2 for this interval). In common with I-1, both spacecraft observed clearly defined signatures of a bursty bulk flow (BBF), as evidenced by the enhancement in $V_{\perp X}$

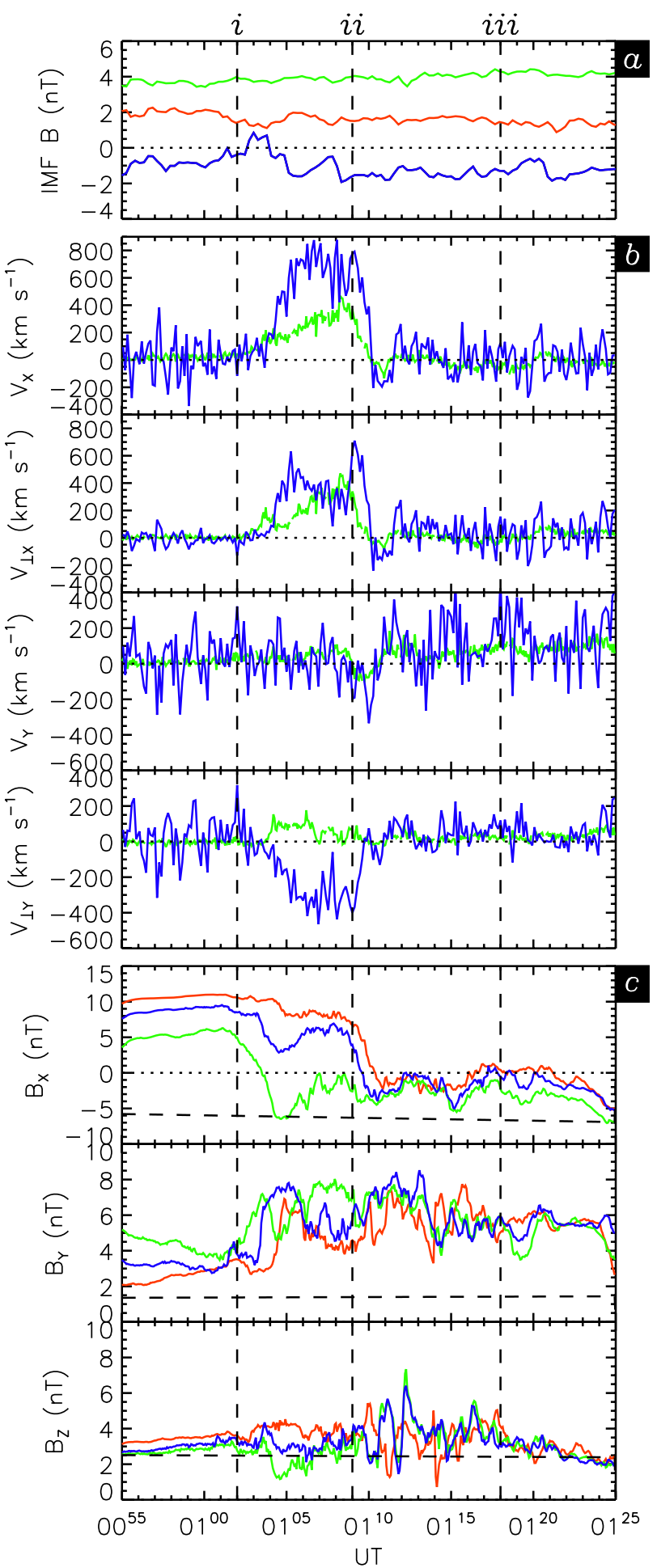

Fig. 5. Time series data from 00:55-01:25 UT on 17 September 2005 in the same format as Fig. 3.

which peaked at 01:09 UT (ii) at a value of $\sim 600 \mathrm{~km} \mathrm{~s}^{-1}$ (as measured by Cluster 4 , at Cluster 3 the peak was measured to be $400 \mathrm{~km} \mathrm{~s}^{-1}$ ). It should be pointed out that owing to 
degradation of the CODIF sensor the data shown for Cluster 3 is from HIA. Unfortunately, Cluster 4 has no working HIA instrument and therefore a like-for-like comparison can not be made. However, the coincident observation of enhanced earthward flows of a few $100 \mathrm{~km} \mathrm{~s}^{-1}$ by different sensors on each spacecraft implies that, at least on the larger scale, they are both observing the bulk plasma motion.

These enhanced flows were accompanied by a perturbation in $B_{Z}$ beginning at 01:02 UT $(i)$ (peaking at $\sim 5 \mathrm{nT}$ after $10 \mathrm{~min})$. Although there is a less significant enhancement during this interval than was observed during I-1, the general trend up to (iii) is that of an increase. Interestingly, however, although there were enhancements in $V_{\perp Y}$ at the time of the BBF there was no such enhancement in $V_{Y}$. This implies that the net motion of the plasma (field-aligned + fieldperpendicular) was earthward, but that the convective motion of the flux did have an azimuthal component. Consider Cluster 4, which observed a positive $B_{X}$ component and was therefore above the neutral sheet, the same as for I-1. The enhancement in $V_{\perp Y}$ in this case was in a dawnward direction, the same as the direction of the TRINNI flows in the Northern Hemisphere ionosphere (Fig. 4a). However, looking at the $B_{X}$ component measured by Cluster 3 reveals that the spacecraft was below the neutral sheet. Here, flows with an opposite $V_{\perp Y}$ were observed, in apparent agreement with the duskward sense of the flows observed in the Southern Hemisphere ionosphere. These observations imply that, although the flow itself was earthward at the location of the spacecraft, the convective motion of the magnetic field had an azimuthal component which was opposite in the two hemispheres. Indeed, looking at $B_{Y}$, although the overall sense is positive (as expected for a twisted tail under positive IMF $B_{Y}$ (Nishida et al., 1994)), smaller-scale perturbations between (i) and (ii) also have the opposite sense between Cluster 3 and 4.

\section{Discussion}

The radar data presented above are consistent with previous observations of non-substorm transient convection enhancements in the nightside high-latitude ionosphere (e.g. Grocott et al., 2003). This enhanced convection is understood to result from bursty nightside reconnection associated with modest solar wind driving at the dayside magnetopause during intervals of northward, but $B_{Y}$-dominated, IMF. These bursts of "tail reconnection during IMF-northward, non-substorm intervals", (TRINNIs) are characterised not only by their ionospheric flows, but also by the lack of accompanying auroral and geosynchronous signatures. Energetic electron data, for example, from the Los Alamos National Laboratory (LANL) spacecraft (not shown) reveal no sign of injection signatures during either interval discussed here. A number of auroral datasets (not shown) also confirm that neither interval is associated with typical substorm activity. Ground magnetometer data from the MIRACLE (Lühr et al., 1998) and

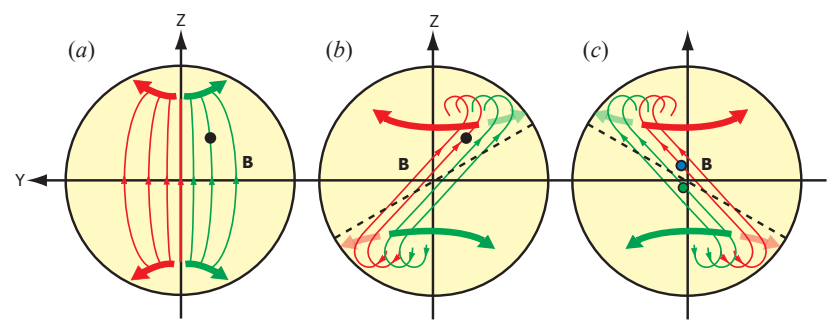

Fig. 6. Schematic view of the Earth from the tail in the GSM $y-z$ plane, with closed plasma sheet field lines represented by the thin arrowed curves and the direction of the TRINNI flow bursts in the ionosphere being indicated by the thick arrowed curves. The field lines and flow bursts are coloured according to whether they reconnected post- (red) or pre- (green) midnight. (a) shows the $B_{Y} \sim 0$ scenario, (b) $B_{Y}<0$ and (c) $B_{Y}>0$. The locations of Cluster 3 and 4 (from I-2) are also indicated in (c) (not to scale) by the green and blue filled circles, respectively.

Greenland (Friis-Christensen et al., 1985) networks, for example, reveal enhancements in the auroral electrojets of only a few tens of nanotesla and negligible low-latitude Pi-2 band (20-200 s) activity. The magnetic field continuation method of Amm and Viljanen (1999) provides values of the associated field-aligned currents of $\sim 100 \mathrm{~mA} \mathrm{~m}^{-1}$ which, when combined with electric field measurements from the radars of $\sim 50 \mathrm{mV} \mathrm{m}^{-1}$ suggests auroral conductivities of just a few S. Auroral imagery from the wideband imaging camera on the far-ultraviolet instrument onboard the IMAGE satellite (Mende et al., 2000a, b) also reveals no significant auroral breakups, although some small, localised, brightenings at $\sim 70^{\circ}$ magnetic latitude during I- 1 are apparent. These may well be related to poleward boundary auroral intensifications (PBIs) or arc "bifurcations" (Lyons et al., 1999) and auroral streamers (Henderson et al., 1998) which have been shown to occur commonly under a wide variety of conditions, both during "quiet" times and during substorms. Why these auroral forms should be present during only one of the intervals discussed here and not be common to all BBF-type activity is an interesting question, but is beyond the scope of the present study.

The primary significance of the observations discussed in this paper then, is that they show that TRINNIs, previously observed only in the ionosphere, have a distinct and identifiable signature in the magnetosphere. They have revealed that, at least in some cases, TRINNIs are associated with bursty bulk flows and, more significantly, that the azimuthal sense of the large-scale flow observed by SuperDARN may also be present on a smaller scale in the magnetosphere. In order to better visualise the implications of these observations consider the illustration in Fig. 6, which depicts the geometry involved in the tail for 3 different scenarios, as viewed looking onto the Earth from the tail. Newly closed plasma sheet field lines are represented by the thin arrowed curves with the direction of ionospheric convection at their 

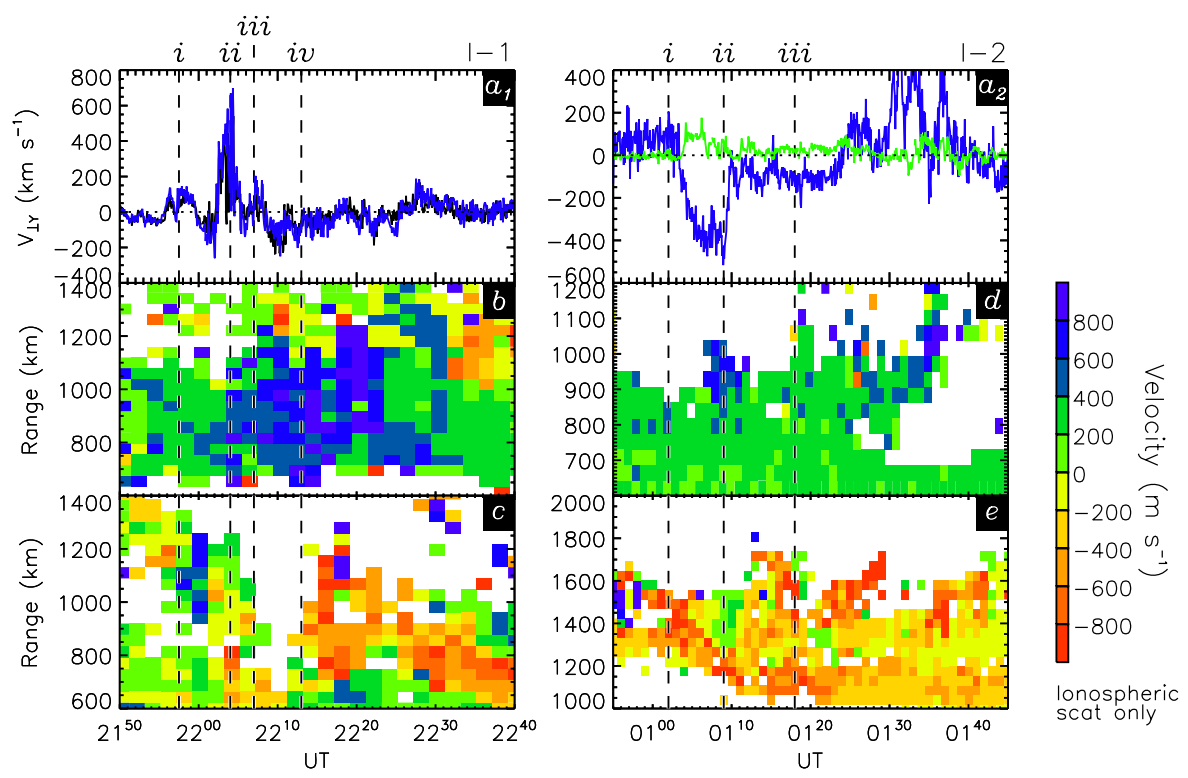

Fig. 7. Time-series data from Cluster and SuperDARN for I-1 (a1, b-c) and I-2 (a2, d-e). Panels $\left(\mathrm{a}_{1}\right)$ and $\left(\mathrm{a}_{2}\right)$ show $\mathrm{V}_{\perp Y}$ from Figs. 3 and 5, respectively. Panels (b-e) show range-time-velocity data from the radar beams indicated in the corresponding panels of Fig. 1, colour coded according to the bar on the right.

footprints indicated by the thick arrowed curves. Figure 6a shows field lines which are symmetrical about the midnight meridian, as might be expected, for example, for IMF $B_{Y}=0$. A spacecraft located at the position of the black circle would then be expected to observe dawnward convection. In Fig. 6b the tail field lines are twisted out of meridian planes by the persistence of negative IMF $B_{Y}$ prior to reconnection (see e.g., Nishida et al., 1998; Grocott et al., 2005; Milan et al., 2005). The thick arrowed curves then show the direction of the TRINNI flow bursts in the ionosphere. The field lines and flow bursts are coloured according to whether they reconnected post- (green) or pre- (red) midnight, thus forming either a Northern Hemisphere (westward) or Southern Hemisphere (eastward) TRINNI. In this case, a spacecraft located at the position of the black circle would observe duskward convection, as was the case in I-1, described above. Finally, Fig. $6 \mathrm{c}$ shows the case for I-2, where the twisting of the tail is that due to positive IMF $B_{Y}$. The locations of Cluster 3 and 4 are now indicated on the figure (not to scale) by the green and blue filled circles respectively. The opposite senses of $B_{X}$ observed by the two spacecraft during the interval confirms that they were on opposite sides of the current sheet and the opposite senses of $V_{\perp Y}$ that they observed, along with the corresponding ionospheric observations in each hemisphere, imply their locations on oppositely moving field lines.

Now, consider the relationship between the ionospheric and magnetospheric manifestations of TRINNIs in more detail. Whilst it is apparent that they can agree in broader terms, their time-dependence does not appear to be identical. Signatures of BBFs in the magnetosphere are intrinsi- cally short lived, lasting of order $\sim 10 \mathrm{~min}$. In the ionosphere the electric field enhancements associated with TRINNIs develop over longer timescales. To aid discussion of this temporal evolution, time-series data summarising the observations of Figs. 2-5 are presented in Fig. 7 for I-1 (21:5022:40 UT) and I-2 (00:55-01:45 UT). These intervals have been extended slightly from those displayed in Figs. 3 and 5 to illustrate the persistence of the radar signatures beyond the times of the Cluster data displayed previously. $V_{\perp Y}$ from each interval is reproduced in panels $\left(a_{1}\right)$ and $\left(a_{2}\right)$ for reference. Panels (b-e) show range-time-velocity SuperDARN data from the radar beams indicated in the corresponding panels of Fig. 1. The colour coding of the radar data is as in Figs. 2 and 4, though it is perhaps worth pointing out that the data presented from I-1 are from oppositely directed radar beams than that from I-2 (see Fig. 1), such that the east/west sense of the blue/red colour scale is effectively reversed for the two intervals.

Looking first at I-1, the Northern Hemisphere flow burst from Fig. 2a is clearly evident in the data shown in Fig. 7b. The enhanced westward (blue) flows can be seen to have developed 2-4 min after the onset of activity in the tail $(i)$, in concert with the peak in flux transport (ii). This flow enhancement continued, however, until at least 22:24 UT, with all evidence of the enhancement not disappearing until 22:34 UT, some $20 \mathrm{~min}$ after the end of the BBF signature. Now consider the corresponding Southern Hemisphere data presented in panel (c) which shows the flow burst from Fig. 2b. In this case, the enhanced eastward (red) flows in the Southern Hemisphere do not appear to have developed until 
after all evidence of the magnetospheric enhancement had subsided (iv). A gap in the coverage of SuperDARN scatter prior to this point might well be responsible for some of the apparent delay, although the enhanced flows in this case persist for longer than their Northern Hemisphere counterpart. A lack of consistency between the timing of Northern and Southern Hemisphere flow bursts is not unexpected however, since they are not geomagnetically conjugate and are not, therefore, constrained to occur simultaneously (Grocott et al., 2005). Turning to the summary for I-2, the Northern Hemisphere data shown in Fig. 7d reveal a clear patch of fast eastward (blue) scatter centred on (ii), which appears $\sim 5 \mathrm{~min}$ after the onset of the eastward flow in the magnetosphere, as evidenced by the Cluster 4 data (the blue curve in panel $a_{2}$ ). Interestingly in this case, the enhancement was short lived ( $\sim 5 \mathrm{~min}$ ), although the flows became enhanced again after 01:30 UT, in concert with Cluster 4 observing an additional enhancement in $V_{\perp Y}$ (now westward, since the spacecraft had moved below the neutral sheet). Finally, the Southern Hemisphere data for this interval, plotted in panel (e), also reveals enhanced flow signatures which persist throughout this extended interval. In this case, however, the first evidence of fast westward (red) flow occurs at $\sim 01: 00 \mathrm{UT}$, slightly prior to the first magnetospheric signatures being observed. Additional enhancements at $\sim 01: 16, \sim 01: 25$ and 01:35 UT are also apparent.

Two possible explanations exist for this lack of consistency between the magnetospheric and ionospheric observations. One is that there are propagation effects resulting in the flows which are initiated in the magnetosphere not being experienced in the ionosphere for some finite time. Another is that the reconfiguration of the tail which is evident in the ionosphere is related to a larger-scale magnetospheric event than previous studies of BBF suggest, or that multiple quanta of smaller-scale magnetospheric events are occurring and that Cluster is only observing one such contribution. In fact, it is likely to be a combination of both temporal and spatial effects. In theory, the minimum time delay between a magnetospheric disturbance being observed in the ionosphere is limited by the Alfvén speed, which is sensitive to variations in the magnetic field strength and plasma density and therefore difficult to integrate along any given field line. Nakamura et al. (2005b) compared the Cluster observations from our I-1 with those from the Double Star (Liu et al., 2005) TC-1 spacecraft, located $\sim 9 R_{E}$ downtail, and found no discernable signature of the dipolarisation front this close to the Earth. It is possible, however, that the significant azimuthal component of the disturbance could be responsible for the delay between the BBF signature at Cluster and ground-based observations made at an earlier local time. This can be investigated by considering, for example, the time at which the ionospheric signature of the BBF was observed by the MIRACLE ground magnetometer network (as discussed by, e.g., Amm and Kauristie, 2002). MIRACLE was located about $1000 \mathrm{~km}$ to the west of the mapped location of the Cluster spacecraft during I-1 and observed the signature of the BBF at 22:12 UT, some $8 \mathrm{~min}$ after the peak signature observed by Cluster. This translates to a propagation speed of $\sim 2 \mathrm{~km} \mathrm{~s}^{-1}$, which is comparable to values discussed by Amm and Kauristie. At this speed, however, it would have taken twice this time for the same BBF to have propagated into the premidnight sector where the peak radar flow enhancement was observed (Fig. 2a). This suggests that either the BBF has a much larger azimuthal extent than previously thought, or that a number of BBFs are occurring across the tail within the timescale of the TRINNI.

Additional information about the relationship between the larger-scale TRINNI activity observed by SuperDARN and isolated BBFs observed locally by Cluster is revealed by consideration of the associated reconnection rates and flux transport. Estimates of total flux closure and associated nightside reconnection rates for TRINNIs have been determined previously, for example, by Grocott et al. (2003) and Milan et al. $(2005,2006)$ to be $\sim 0.1-0.2 \mathrm{GWb}$ and $\sim 35 \mathrm{kV}$, respectively. These estimates were based on large-scale ionospheric observations from auroral and radar data. Estimates of the in-situ flux transport associated with BBFs have been determined by Angelopoulos et al. (1994) and Schödel et al. (2001a) to be $\sim 2 \times 10^{6} \mathrm{~Wb} R_{E}^{-1}$. If BBFs are responsible for transporting all the flux closed in a typical TRINNI, then this implies either a $100 R_{E}$ scale size for the BBFs in question, or that a large number of localized BBFs contribute to the large-scale convection. The latter is more probable, since the timeframe of observations of BBFs is of the order of $10 \mathrm{~min}$, whereas TRINNI activity has been observed to last for in excess of an hour (e.g. Milan et al., 2006). Grocott et al. (2004a) compared in-situ measurements of flux transport (at similar levels to those observed by Angelopoulos et al., 1994, and Schödel et al., 2001a) made by Cluster to observations of the ionospheric flow perturbation associated with an isolated BBF. They observed a localised ionospheric voltage enhancement of $\sim 10 \mathrm{kV}$ which, over the $\sim 10$ min duration of the event corresponds to $\sim 6 \times 10^{6} \mathrm{~Wb}$. If this enhancement was due solely to the action of the BBF then this would imply a scale size of $\sim 3 R_{E}$ in the magnetosphere which is more consistent with previous observations (e.g. Sergeev et al, 1990, 1996; Angelopoulos et al., 1997; Kauristie et al., 2000; Nakamura et al., 2001).

In order to make a similar comparison for the events studied here, the criterion of Schödel et al. (2001a) is used to define the horizontal electric field $E_{H}$ (Eq. 1), which is then integrated between (i) and (iv) from Fig. 3 (and (i) and (iii) from Fig. 5) to find the flux transport per $R_{E}, \Phi_{H}$ :

$\Phi_{H}=\int_{t_{i}}^{t_{i v}} E_{H} \cdot d t=\int_{t_{i}}^{t_{i v}} \sqrt{\left(V_{X} B_{Z}\right)^{2}+\left(V_{Y} B_{Z}\right)^{2}} \cdot d t$

This yields values of $2.25 \times 10^{6} \mathrm{~Wb} R_{E}^{-1}$ (at Cluster 1) and $2.86 \times 10^{6} \mathrm{~Wb} R_{E}^{-1}$ (at Cluster 4) for I-1 and $1.11 \times 10^{6} \mathrm{~Wb} R_{E}^{-1}$ (at Cluster 3) and $3.10 \times 10^{6} \mathrm{~Wb} R_{E}^{-1}$ (at 
Cluster 4) for I-2. These values are again comparable to those reported by Angelopoulos et al. (1994) and Schödel et al. (2001a). The electric field measured in the ionosphere, corresponding to flows of $\sim 1000 \mathrm{~m} \mathrm{~s}^{-1}$, is $\sim 50 \mathrm{mV} \mathrm{m}^{-1}$. This is a factor of 10 greater than the local electric field associated with the BBF, presumably resulting from the convergence of field lines in the ionosphere. By putting an upper limit on the width of the flow channels in the ionosphere (from Figs. 2 and 4 ) of $\sim 500 \mathrm{~km}$ this then implies a scale size for the BBF in the magnetosphere of $\sim 1 R_{E}$. It also implies an associated ionospheric voltage of $\sim 25 \mathrm{kV}$ which is consistent with the studies discussed above. However, the fact that the ionospheric flows persist significantly longer than the BBF timescale implies that there are likely to be multiple BBFs contributing to the overall large-scale convection.

\section{Summary}

Azimuthal bursts of flow in the nightside, high-latitude ionosphere which have previously been associated with "tail reconnection during IMF-northward, non-substorm intervals" (TRINNIs) by Grocott et al. (2003, 2004b, 2005) and Milan et al. (2005), have been observed in concert with signatures of flux transport in the magnetosphere. These magnetospheric signatures resemble Bursty Bulk Flows (BBFs) or Rapid Flux Transport events (RFTs) as described by Angelopoulos et al. (1994) and Schödel et al. (2001a), taking the form of $\sim 10$ min timescale bursts of $\sim 800 \mathrm{~km} \mathrm{~s}^{-1}$ earthward flow in the central plasma sheet. Atypically however, these BBFs also revealed some azimuthal asymmetry, which matched that of the TRINNI flows observed in the ionosphere. Observations from opposite sides of the neutral sheet also revealed convective flows with opposite azimuthal direction. This was consistent with interhemispheric observations of the ionospheric flow, corroborating the idea that TRINNIs are formed by the effect of reconnection on field lines which have been twisted out of meridian planes by the penetration of IMF $B_{Y}$ into the tail. Values of flux transport associated with these bursts of reconnection have been calculated to be $\sim 2 \times 10^{6} \mathrm{~Wb} R_{E}^{-1}$, compared to values of ten times this over similar timescales in the ionosphere, suggesting a lack of one-to-one correlation between BBFs and the large-scale convection associated with TRINNIs. Time-series analysis of the ionospheric data confirms this to be the case, indicating that the flows can persist for in excess of $30 \mathrm{~min}$ after the magnetospheric signatures subside. This implies that multiple, localised, quanta of magnetospheric flux transport contribute to the overall large-scale convection which is evident in the ionosphere.

Acknowledgements. Thanks to the PIs of the SuperDARN radars for provision of the radar data employed in this study. Thanks also G. Chisham and E. Mravlag for their assistance in obtaining the Southern Hemisphere data. SuperDARN is funded by the research funding agencies of Canada, France, Japan, South Africa, Australia, the UK, and USA. For provision of ACE magnetometer we thank Norman Ness and Charles Smith of the Bartol Research Institute. A. Grocott was supported during this study by PPARC grant PPA/G/O/2003/00013. SuperDARN operations at the University of Leicester are supported by PPARC grant PPA/R/R/1997/00256. Collaborative effort was facilitated during this study by the European Planetology Network (Europlanet).

Topical Editor I. A. Daglis thanks two anonymous referees for their help in evaluating this paper.

\section{References}

Amm, O. and Kauristie, K.: Ionospheric signatures of bursty bulk flows, Surv. Geophys., 23, 1-32, 2002.

Amm, O. and Viljanen, A.: Ionospheric disturbance magnetic field continuation from the ground to the ionosphere using spherical elementary current systems, Earth, Planets and Space, 51, 431440, 1999.

Angelopoulos, V., Baumjohann, W., Kennel, C. F., Coroniti, F. V., Kivelson, M. G., Pellat, R., Walker, R. J., Lühr, H., and Paschmann, G.: Bursty bulk flows in the central plasma sheet, J. Geophys. Res., 97, 4027-4039, 1992.

Angelopoulos, V., Kennel, C. F., Coroniti, F. V., Pellat, R., Kivelson, M. G., Walker, R. J., Russell, C. T., Baumjohann, W., Feldman, W. C., and Gosling, J. T.: Statistical characteristics of bursty bulk flow events, J. Geophys. Res., 99, 21 257-21 280, 1994.

Angelopoulos, V., Phan, T. D., Larson, D. E., et al.: Magnetotail flow bursts: association to global magnetospheric circulation, relationship to ionospheric activity and direct evidence for localization, Geophys. Res. Lett., 24, 2271-2274, 1997.

Baker, D. N., Pulkkinen, T. I., Angelopoulos, V., Baumjohann, W., and McPherron, R. L.: Neutral line model of substorms: Past results and present view, J. Geophys. Res., 101, 12 975-13010, 1996.

Balogh, A., Carr, C. M., Acuña, M.-H., Dunlop, M. W., Beek, T. J., Brown, P., Fornacon, K.-H., Georgescu, E., Glassmeier, K.H., Harris, J. P., Musmann, G. Oddy, T. M., and Schwingenschuh, K.: The Cluster magnetic field investigation: Overview of in-flight performance and initial results, Ann. Geophys., 19, 1207-1217, 2001, http://www.ann-geophys.net/19/1207/2001/.

Baumjohann, W., Paschmann, G., and Lühr, H.: Characteristics of high-speed flows in the plasma sheet, J. Geophys. Res., 95, 3801-3809, 1990.

Dungey, J. W.: Interplanetary magnetic field and the auroral zones, Phys. Rev. Lett., 6, 47-49, 1961.

Farrugia, C. J., Freeman, M. P., Burlaga, L. F., Lepping, R. P., and Takahashi, K.: The Earth's magnetosphere under continued forcing: Substorm activity during the passage of an interplanetary magnetic cloud, J. Geophys. Res., 98, 7657-7671, 1993.

Friis-Christensen, E., Kamide, Y., Richmond, A. D., and Matsushita, S.: Interplanetary magnetic field control of high-latitude electric fields and currents determined from Greenland magnetometer data, J. Geophys. Res., 90, 1325-1338, 1985.

Greenwald, R. A., Baker, K. B., Dudeney, J. R., Pinnock, M., Jones, T. B., Thomas, E. C., Villain, J.-P., Cerisier, J.-C., Senior, C., Hanuise, C., Hunsucker, R. D., Sofko, G., Koehler, J., 
Nielsen, E., Pellinen, R., Walker, A. D. M., Sato, N., and Yamagishi, H.: DARN/SuperDARN: A global view of the dynamics of high-latitude convection, Space Sci. Rev., 71, 761-796, 1995.

Grocott, A., Cowley, S. W. H., Sigwarth, J. B., Watermann, J. F., and Yeoman, T. K.: Excitation of twin-vortex flow in the nightside high-latitude ionosphere during an isolated substorm, Ann. Geophys., 20, 1577-1601, 2002,

http://www.ann-geophys.net/20/1577/2002/.

Grocott, A., Cowley, S. W. H., and Sigwarth, J. B.: Ionospheric flows and magnetic disturbance during extended intervals of northward but $\mathrm{B}_{y}$-dominated IMF, Ann. Geophys., 21, 509-538, 2003,

http://www.ann-geophys.net/21/509/2003/.

Grocott, A., Yeoman, T. K., Nakamura, R., Cowley, S. W. H., Rème, H., and Klecker, B.: Multi-instrument observations of the ionospheric counterpart to a bursty bulk flow in the nearEarth plasma sheet, Ann. Geophys., 22, 1061-1075, 2004a.

Grocott, A., Badman, S. V., Cowley, S. W. H., Yeoman, T. K., and Cripps, P. J.: The influence of IMF $B_{y}$ on the nature of the nightside high-latitude ionospheric flow during intervals of positive IMF $B_{z}$, Ann. Geophys., 22, 1755-1764, 2004b.

Grocott, A., Yeoman, T. K., Milan, S. E., and Cowley, S. W. H.: Interhemispheric observations of the ionospheric signature of tail reconnection during IMF-northward non-substorm intervals, Ann. Geophys., 23, 1763-1770, 2005,

http://www.ann-geophys.net/23/1763/2005/.

Henderson, M. G., Reeves, G. D., and Murphree, J. S.: Are northsouth aligned auroral structures an ionospheric manifestation of bursty bulk flows?, Geophys. Res. Lett., 25, 3737-3740, 1998.

Heppner, J. P., and Maynard, N. C.: Empirical high-latitude electric field models, J. Geophys. Res., 92, 4467-4489, 1987.

Hones Jr., E. W.: Transient phenomena in the magnetotail and their relation to substorms, Space Sci. Rev., 23, 393-410, 1979.

Kauristie, K, Sergeev, V. A., Kubyshkina, M., Pulkkinen, T. I., Angelopoulos, V., Phan, T., Lin, R. P., and Slavin, J. A.: Ionospheric current signatures of transient plasma sheet flows, J. Geophys. Res., 105, $10677-10690,2000$.

Khan, H. and Cowley, S. W. H.: Observations of the response time of high latitude ionospheric convection to variations in the interplanetary magnetic field using EISCAT and IMP-8 data, Ann. Geophys., 17, 1306-1335, 1999, http://www.ann-geophys.net/17/1306/1999/.

Liu, Z. X., Escoubet, C. P., Pu, Z., Laakso, H., Shi, J. K., Shen, C., and Hapgood, M.: The Double Star mission, Ann. Geophys., 23, 2707-2712, 2005, http://www.ann-geophys.net/23/2707/2005/.

Lühr, H., Aylward, A., Buchert, S. C., Pajunpää, A., Pajunpää, K., Holmboe, T., and Zalewski, S. M.: Westward moving dynamic substorm features observed with the IMAGE magnetometer network and other ground-based instruments, Ann. Geophys., 16, 425-440, 1998,

http://www.ann-geophys.net/16/425/1998/.

Lyons, L. R., Nagai, T., Blanchard, G. T., Samson, J. C., Yamamoto, T., Mukai, T., Nishida, A., and Kokubun, S.: Association between Geotail plasma flows and auroral poleward boundary intensifications observed by CANOPUS photometers, J. Geophys. Res., 104, 4485-4500, 1999.

McComas, D. J., Bame, S. J., Barker, P., Feldman, W. C., Phillips, J. L., Riley, P., and Griffee, J. W.: Solar Wind Electron Proton
Alpha Monitor (SWEPAM) for the Advanced Composition Explorer, Space Sci. Rev., 86, 563-612, 1998.

Mende, S. B., Heetderks, H., Frey, H. U., Lampton, M., Geller, S. P., Habraken, S., Renotte, E., Jamar, C., Rochus, P., Spann, J., Fuselier, S. A., Gerard, J.-C., Gladstone, R., Murphree, S., and Cogger, L.: Far ultraviolet imaging from the IMAGE spacecraft. 1. System design, Space Sci. Rev., 91, 243-270, 2000a.

Mende, S. B., Heetderks, H., Frey, H. U., Lampton, M., Geller, S. P., Abiad, R., Segmund, O. H. W., Tremsin, A. S., Span, J., Dougani, H., Fuselier, S. A., Magoncelli, A. L., Bumala, M. B., Murphree, S., and Trondsen, T.: Far ultraviolet imaging from the IMAGE spacecraft. 2. Wideband FUV imaging, Space Sci. Rev., 91, 271-285, 2000b.

Milan, S. E., Hubert, B., and Grocott, A.: Formation and motion of a transpolar arc in response to dayside and nightside reconnection, J. Geophys. Res., 110, doi:10.1029/2004JA010835, 2005.

Milan, S. E., Wild, J. A., Grocott, A., and Draper, N. C.: Spaceand ground-based investigations of solar wind-magnetosphereionosphere coupling, Adv. Space. Res., 38, 1671-1677, 2006.

Nagai, T., Fujimoto, M., Saito, Y., Machida, S., Teresawa, T., Nakamura, R., Yamamoto, T., Mukai, T., Nishida, A., and Kokubun, S.: Structure and dynamics of magnetic reconnection for substorm onsets with Geotail observations, J. Geophys. Res., 103, 4419-4440, 1998.

Nakamura, R., Baumjohann, W., Schödel, R., Brittnacher, M., Sergeev, V. A., Kubyshkina, M., Mukai, T., and Liou, K.: Earthward flow bursts, auroral streamers, and small expansions, J. Geophys. Res., 106, 10 791-10 802, 2001.

Nakamura, R., Amm, O., Laakso, H., Draper, N. C., Lester, M., Grocott, A., Klecker, B., McCrea, I. W., Balogh, A., Rème, H., and André, M.: Localized fast flow disturbance observed in the plasma sheet and in the ionosphere, Ann. Geophys., 23, 553-566, 2005a.

Nakamura, R., Baumjohann, W., Zhang, T.L., Carr, C. M., Balogh, A., Fornacon, K. H., Georgescu, E., Rème, H., Dandouras, I., Takada, T., Volwerk, M., Asano, Y., Runov, A., Eichelberger, H., Klecker, B., Mouikis, C., Kistler, L. M., and Amm, O.: Cluster and Double Star observations of dipolarization, Ann. Geophys., 23, 2915-2920, 2005b.

Nishida, A., Yamamoto, T., Tsuruda, K., Hayakawa, H., Matsuoka, A., Kokubun, S., Nakamura, M., and Maezawa, K.: Structure of the neutral sheet in the distant tail $\left(\mathrm{x}=-210 R_{e}\right)$ in geomagnetically quiet times, Geophys. Res. Lett., 21, 2951-2954, 1994.

Nishida, A., Mukai, T., Yamamoto, T., Saito, Y., Kokubun, S., and Maezawa, K.: GEOTAIL observations of magnetospheric convection in the distant tail at $200 R_{E}$ in quiet times, J. Geophys. Res., 100, 23 663-23 675, 1995.

Nishida, A., Mukai, T., Yamamoto, T., Kokubun, S., and Maezawa, K.: A unifield model of the magnetotail convection in geomagnetically quiet and active times, J. Geophys. Res., 103, 4409-4418, 1998.

Provan, G., Lester, M., Mende, S. B., and Milan, S. E.: Statistical study of high-latitude plasma flow during magnetospheric substorms, Ann. Geophys., 22, 3607-3624, 2004, http://www.ann-geophys.net/22/3607/2004/.

Rème, H., Aoustin, C., Bosqued, J. M., et al.: First multispacecraft ion measurements in and near the Earth's magnetosphere with the identical Cluster ion spectrometry (CIS) experiment, Ann. Geophys., 19, 1303-1354, 2001, 
http://www.ann-geophys.net/19/1303/2001/.

Ruohoniemi, J. M. and Baker, K. B.: Large-scale imaging of highlatitude convection with Super Dual Auroral Radar Network HF radar observations, J. Geophys. Res., 103, 20 797-20 811, 1998.

Ruohoniemi, J. M. and Greenwald, R. A.: Statistical patterns of high-latitude convection obtained from Goose Bay HF radar observations, J. Geophys. Res., 101, 21 743-21 763, 1996.

Sandholt, P. E., Farrugia, C. J., Moen, J., and Cowley, S. W. H.: Dayside auroral configurations: Responses to southward and northward rotations of the interplanetary magnetic field, J. Geophys. Res., 103, 20 279-20 295, 1998a.

Sandholt, P. E., Farrugia, C. J., Moen, J., Noraberg, Ø., Lybekk, B., Sten, T., and Hansen, T.: A classification of dayside auroral forms and activities as a function of IMF orientation, J. Geophys. Res., 103, 23 325-23 345, 1998 b.

Schödel, R., Baumjohann, W., Nakamura, R., Sergeev, V. A., and Mukai, T.: Rapid flux transport in the central plasma sheet, J. Geophys. Res., 106, 301-313, 2001 a.

Schödel, R., Nakamura, R., Baumjohann, W., and Mukai, T.: Rapid flux transport and plasma sheet reconfiguration, J. Geophys. Res., 106, 8381-8390, 2001b.

Sergeev, V. A., Aulamo, O. A., Pellinen. R. L., Vallinkoski, M. K., Bosinger, T., Cattell, C. A., Elphic, R. C., and Williams, D. J.: Non-substorm short-lived injection events in the ionosphere and magnetosphere, Planet. Space Sci., 38, 231-239, 1990.
Sergeev, V. A., Angelopoulos, V., Gosling, J. T., Cattell, C. A., and Russell, C. T.: Detection of localized, plasma-depleted flux tubes or bubbles in the midtail plasma sheet, J. Geophys. Res., 101, 10 817-10 826, 1996.

Shepherd, S. G. and Ruohoniemi, J. M.: Electrostatic potential patterns in the high-latitude ionosphere constrained by SuperDARN measurements, J. Geophys. Res., 105, 23 005-23 014, 2000.

Smith, C. W., Acuña, M. H., Burlaga, L. F., L'Heureux, J., Ness, N. F., and Scheifele, J.: The ACE Magnetic Field Experiment, Space Sci. Rev., 86, 613-622, 1999.

Stone, E. C., Frandsen, A. M., Mewaldt, R. A., Christian, E. R., Margolies, D., Ormes, J. F., and Snow, F.: The Advanced Composition Explorer, Space Sci. Rev., 86, 1-22, 1998.

Taguchi, S.: $B_{y}$-controlled field-aligned currents near midnight auroral oval during northward interplanetary magnetic field, J. Geophys. Res., 97, 12 231-12 243, 1992.

Taguchi, S. and Hoffman, R. A.: Ionospheric plasma convection in the midnight sector for northward interplanetary magnetic field, J. Geomag. Geoelectr., 48, 925-933, 1996.

Taguchi, S., Sugiura, M., Iyemori, T., Winningham, J. D., and Slavin, J. A.: $B_{y}$-controlled convection and field-aligned currents near midnight auroral oval for northward interplanetary magnetic field, J. Geophys. Res., 99, 6027-6044, 1994.

Tsyganenko, N. A.: Modeling the Earth's magnetospheric magnetic field confined within a realistic magnetopause, J. Geophys. Res., 100, 5599-5612, 1995. 